\title{
Research on Group Emotional Intelligence Effects on Group Decision-making under Emergency
}

\author{
Yingxin Chen \\ School of Economics and Management, Harbin Engineering University, Harbin \\ 150001, China \\ chenyxdingdang@hrbeu.edu.cn
}

\begin{abstract}
After various types of emergencies, victims and rescuers will have negative psychological and mental reactions, such as stress response, psychological disorder. In this case, making the right group decision is the most important issue. It proposes the concept model of group emotional intelligence, adopts $2 \times 2$ factorial design, carries on survival experiment including 52 groups, and analyzes the influence of the group emotional intelligence on intra-group conflict, conflict management, performance, satisfaction and cohesion. Utilizes the statistical software SPSS19.0 for data analysis, and draws reliable conclusions. The conclusions offer references for enhancing emotional management capacity and problem-solving abilities of decision-making groups in emergencies environment.
\end{abstract}

Keywords: Emergency management; group emotional intelligence; group decision; survival experiment

\section{Introduction}

Along with speeding course of industrialization and globalization in recent years, all kinds of accidents happen frequently which have influenced the social stability and people's life. The Chinese government needs to enhance emergency management, which is the pressing need and major guarantee of raising government's administrative abilities and building as service-oriented government [1]. On November 1, 2007, the Chinese government issued the emergency corresponding law of the People's Republic of China. In 2009, the Natural Science Foundation of China officially launched a major project 'The Research on Unconventional Emergency Management', which promotes the development of emergency management system tremendously. For different incidents, concrete manifestations and characteristics are different, but one thing is the same, that is the number of affected people is so large that it will lead to group behavior, so it is necessary to do a research on group behavior.

The goal of this research is to analyze effects of group emotional intelligence on group decision-making under emergency, and explore the emotional problems in group decision making process through scientific experiment method. The research conclusions provide significant references to enhance capacity of emotional management and improve victim's problem-solving abilities.

\section{Literature Review}

\subsection{Group Decision-making}

An increasing number of modern organizations rely on communication, coordination and brainstorm group members to solve issues. That, at a very general level defines group 
decision-making. The key of group decision-making is how to obtain good decision results and because group decision-making is part of group interaction course, therefore, group decision result is the group performance during decision-making [2].In the realm of group decision-making, three aspects which have attracted more attention are as follows.

1) Performance of group decision-making $(P)$. Previous research on group decision making, mostly focus on the group performance, the ultimate goal is to identify factors of improving group performance. This paper have more emphasis on task solving in group performance, it mainly refers to effectiveness of decision-making plan by group members' coordination, such as quality of group decision-making, efficacy of group decision-making.

2) Satisfaction of group decision-making $(S)$. In the field of psychology and decision theory, satisfaction is an important indicator to measure the quality of group decision-making. Satisfaction could be seemed as positive outcome of group interpersonal communication. Satisfaction includes group members' process satisfaction $(P S)$ and outcomes satisfaction $(O S)$ $[3,4]$. $P S$ refers to measure the efficiency, coordination, fairness and comprehensibility during the group decision making process, $O S$ refers to the satisfaction of group members on group plan quality and confidence on the correctness of group scheme. Research shows that, distinguish between two kinds of satisfaction is reasonable and necessary, because group member often satisfied with outcomes but not satisfied with process in reality [5].

3) Group cohesion $(\mathrm{COH})$. $\mathrm{COH}$ gets much attention as the very important research object in social psychology and group studies. Based on the previous studies, Bollen and Hoyle presents the concept of perceived cohesion, they all ascribe perceived cohesion as individual members playing the role in group, which reflect assessment of individual to group relationship [7].

\subsection{Group Emotional Intelligence}

Abroad, the concept of 'group emotional intelligence' is explicitly putted forward for the first time in 1999 by Druskat and Wolff, which means the group's ability formed by certain ways to manage the emotional process norm, and cultivate sense of trust, sense of identity, and sense of efficacy among group members through the norm [8]. Based on Druskat and Wolff's theoretical framework, Hamme developed the first group emotional intelligence scale, that is scale of Emotional Competence Group Norms(ECGN), Which has good reliability, polymerization and distinctiveness validity in North America[9]. Combination of Steiner's theory of group task classification, Côte presented a method to measure group emotional intelligence. Concerning additive task, individuals' average is used to measure group emotional intelligence. Concerning conjunctive task, group emotional intelligence is estimated by the worst performance of group members. Concerning disjunctive task, group emotional intelligence is estimated by the best performance of group members [10]. Tongxun Wang explicitly put forward the concept of team emotion quotient for the first time in 1998 at home [11], he indicated that the team emotion quotient is the capacity of controlling and regulating comprehensive mood, and there are three important aspects of group emotional intelligence, which are group average, leadership level and the overall level after interaction among group members. In China, researches on group emotional intelligence are mostly following this thread, but there is no related measurement instrument and empirical test [12].

The remainder of the paper contains the following sections. Section 3 proposes concept definition and research hypothesis, including the definition of group emotional intelligence and some hypothesis about three features of group emotional intelligence. Section 4 introduces the experimental design, experimental samples, the experimental task, the experiment measuring tools and implementation process. Section 5 carries out operation test, 
hypothesis testing. Section 6 discusses the experimental results. Finally, Section 7 presents the concluding remarks and directions for future research.

\section{Concept Definitions and Research Hypothesis Introduction}

This paper defines the group emotional intelligence as the capacity of group member to perceive, regulate and use the group emotion. It includes 4 dimensions; they are group selfawareness of emotion (GSAE), group regulation of emotion (GRE), group using of emotion (GUE) and group interpersonal understanding of emotion (GIUE). Group emotional intelligence consists of three features as follows: 1) Group Average Emotional Intelligence (GAEI), 2) Group Leader Emotional Intelligence (GLEI), 3) Whole Group Emotional Intelligence (WGEI).

We propose hypothesis as follows:

Assumption 1: High GAEI groups will have higher levels of WGEI than low GAEI groups.

Assumption 2: High GLEI groups will have higher levels of WGEI than low GLEI groups.

Assumption 3: High GAEI groups will have higher levels of group decision-making performance than low GAEI group.

Assumption 4: High GLEI groups will experience higher levels of group decision-making performance than low GLEI groups.

Assumption 5: High GAEI groups will experience higher levels of process satisfaction than low GAEI groups.

Assumption 6: High GLEI groups will experience higher levels of process satisfaction than low GLEI groups.

Assumption 7: High GAEI groups will have higher levels of cohesion than low GAEI groups.

Assumption 8: High GLEI groups will have higher levels of cohesion than low GLEI groups.

\section{Experimental Method}

\subsection{Experimental Design}

There are two independent variables in the experiment, they are GAEI and GLEI, and they have two levels respectively, high level and low level, thus it is a $2 * 2$ factors experimental design, including four types of groups, they are GLEIH-GAEIH(means GLEIhighGAEIhigh),GLEIH-GAEIL(means GLEIhigh-GAEIlow),GLEIL-GAEIH(means GLEIlowGAEIhigh),GLEIL-GAEIL(means GLEIlow-GAEIlow). Specific experimental variables illustrated in Table 1.

Table 1. Experimental Variables

\begin{tabular}{cc}
\hline Variable Types & Variable Names \\
\hline Independent & GAEI and GLEI \\
Variables & Group Size (trios and foursome) \\
Control Variables & WGEI (Emotional Intelligence of Whole Group) $P$ (Performance)、PS \\
Dependent & (Process satisfaction)、COH (Cohesion)、COO (Cooperation)、COM \\
Variables & (Competing)、A (Avoiding) \\
\hline
\end{tabular}

Experimental Samples are students from sophomore to senior, and teachers from Harbin engineering university. The sample consists of 381 people, including 281 students, 100 teachers, 164 male, 217 female, the total number of $43 \%$ and $57 \%$ respectively. Subjects 
completed the personal emotion questionnaire, and 191 students and teachers were randomly selected to be pilot experimental sample, and the remaining 190 teachers and students as a formal experimental sample.

The pilot experiment select the desert survival task, and formal experiment select lost in the jungle task. This task is assumed that the experimental group's plane is crash and fall into African jungle, and there are 14 items with them. The participants need to discuss about how to choose 14 items in order of importance? Where to use them? How to use them? How to escape from the forest? The two tasks are survival tasks; both of them have emergency characteristics of unexpectedness, destructiveness, durability, derivation and uncertainty.

The measurement scale includes two categories, individual questionnaire and group questionnaire. The individual questionnaire is conducted before the start of the experiment, and mainly used for personal information collection and personal emotional intelligence investigation.

\subsection{Experimental Procedure}

Above all, subjects complete jungle lost task independently, personal sort the importance of 14 items, moreover, groups and assign roles to them. Leadership role and group arrangement are arranged based on personal emotional intelligence score in advance. The grouping and arrangement of roles in the formal experiment has been previously determined, but the subjects did not know. The reliabilities of WEIS and WLEIS scales are 0.636 and 0.857.WEIS and WLEIS scales are high correlation $(\mathrm{r}=0.323, \mathrm{p}<0.01)$, and each dimension of WEIS and WLEIS are also strong correlation. It indicates that the emotional intelligence scale based on ability test can better reflect four dimensions of emotional intelligence, and have higher reliability. It is reasonable to adopt WEIS as the basis of grouping.

182 ( 8 subjects quit) subjects were grouped in the formal experiment. The grouping thread as follows: First of all, ranking the 182 subjects according to their individual emotional intelligence score, and dividing into two same number groups, the high score group and the low score group (91 per group), furthermore, randomly selecting 26 subjects take a leadership role from the high score group and the low score group respectively, they represent respectively the high emotional intelligence leadership (GLEIH) and low emotional intelligence leadership (GLEIL), moreover, there are remaining 65 subjects in the high score group and the low score group respectively, which are randomly divided into 26 groups, including 13 groups of twosome and 13 groups of trios, which represent respectively high/low average emotional intelligence (GAEIH/GAEIL),finally, GLEIH/GLEIL are randomly paired with GAEIH/GAEIL, and form four types of groups, GLEIH-GAEIH, GLEIH-GAEIL, GLEIL-GAEIH,GLEIL-GAEIL.

A total of 52 groups in the formal experiment (trios and foursome are 26 groups respectively), including 13 GAEIH-GLEIH groups, 15 GAEIH-GLEIL groups, 14 GAEILGLEIH groups and 10 GAEIL-GLEIL groups. In the process of group discussion, we remind each team leader in different time, and ask them to grasp the task schedule according to the rest time, perform their duties of leadership.

\section{Results Analysis}

The results analysis mainly use SPSS 19.0 for Windows, the SPSS statistical methods include basic descriptive statistic, $t$-test, factor analysis, reliability analysis, variance analysis and multiple regression analysis.

The results of descriptive statistic and $t$-test of groups are shown in Table 3. 
Table 3. Results of Descriptive Statistics and $t$-test

\begin{tabular}{llllcc}
\hline GROUP & N & Mean & S.D. & Std.Error Mean & T \\
\hline GAEIH & 27 & 27.938 & 1.512 & 0.286 & $6.814^{* * *}$ \\
GAEIL & 25 & 22.929 & 2.487 & 0.479 & \\
GLEIH & 28 & 29.398 & 2.483 & 0.461 & $11.337 * * *$ \\
GLEIL & 24 & 20.449 & 2.459 & 0.482 & \\
\hline
\end{tabular}

Note: $* * *$ represents $p<0.001$

As seen from the table, variables control are successful, group average emotional intelligence level of GLEIH-GAEIH and GLEIL-GAEIH are significantly higher than GLEIHGAEIL and GLEIL-GAEIL ( $t=6.814, p<0.001)$; leadership emotional intelligence level of GLEIH-GAEIH and GLEIH-GAEIL are significantly higher than GLEIL-GAEIH and GLEILGAEIL ( $t=11.337, p<0.001)$. Therefore, we believe that adopted this grouping is reasonable in the subsequent analysis.

To carry on the $t$-test to variable in this study, these variables are polymerization through the individual level data. The study adopt ICC (Intra-class Correlation Coefficient) index to examine each variable in group whether convergence, in order to judge whether individual level measurement is suitable for polymerization into group level measurement.

First of all, we find that these variables change between groups are significantly higher than within group change through variance analysis $(p<0.05)$ which shows that the difference between groups is higher than it between the group internal members and the group internal has high consistency. Then, ICC value is calculated. The ICC has two kinds of calculation method, ICC (1) is a good approach when subject numbers in each group is different, and ICC (2) is a good approach when subject numbers in each group is the same, to calculate [13]. Because subject numbers in each group is different in this experiment, we use ICC (1) to calculate group convergence degree. The ICC(1) value of COO,COM,A,WGEI,PS, COH are $0.171,0.079,0.033,0.172,0.191$ and 0.105 respectively, the average ICC (l) value of all variables is 0.125 , which between $0.05-0.20$ is suitable for polymerization into group level variables[14].Making individual level variables polymerize to group level variables accordingly. T-test results show that there are no significant difference between trios and foursome. So in the subsequent analysis, the two types of group no longer distinguish.

We adopt multivariate analysis of variance method to test hypotheses. The results of variance analysis as shown in Table 4.

Table 4. Results of MANOVA

\begin{tabular}{|c|c|c|c|c|c|c|}
\hline $\begin{array}{l}\text { Independent } \\
\text { Variable }\end{array}$ & $\begin{array}{l}\text { Dependent } \\
\text { Variable }\end{array}$ & Values of $F$ & $\begin{array}{l}\text { Dependent } \\
\text { Variable }\end{array}$ & Values of $\mathrm{F}$ & $\begin{array}{l}\text { Dependent } \\
\text { Variable }\end{array}$ & Values of $\mathrm{F}$ \\
\hline \multirow[t]{4}{*}{ GAEI } & $C S A E$ & 2.412 & WGEI & 5.858 & $P$ & 0.002 \\
\hline & $G R E$ & $6.355^{*}$ & $\mathrm{COO}$ & $8.661^{* *}$ & $P S$ & $14.616^{* * *}$ \\
\hline & $G U E$ & 2.051 & COM & $4.108^{*}$ & $\mathrm{COH}$ & $7.302^{* *}$ \\
\hline & GIUE & $6.282^{*}$ & $A$ & 0.381 & - & - \\
\hline \multirow[t]{4}{*}{ GLEI } & $G S A E$ & 0.526 & WGEI & 1.365 & $P$ & 1.868 \\
\hline & $G R E$ & $2.852^{+}$ & $\mathrm{COO}$ & 0.151 & $P S$ & 0.576 \\
\hline & $G U E$ & 0.533 & COM & 0.039 & $\mathrm{COH}$ & 1.282 \\
\hline & GIUE & 0.431 & $A$ & 0.003 & - & - \\
\hline \multirow[t]{4}{*}{$G A E I^{*} G L E I$} & CSAE & 0.015 & WGEI & 0.061 & $P$ & 0.327 \\
\hline & GRE & 0.356 & $\mathrm{COO}$ & 0.011 & $P S$ & 0.622 \\
\hline & $G U E$ & 0.000 & COM & 0.002 & $\mathrm{COH}$ & $5.182^{*}$ \\
\hline & GIUE & 0.009 & $A$ & 1.191 & - & - \\
\hline
\end{tabular}

Note: * represents $\mathrm{p}<0.05 ; * *$ represents $\mathrm{p}<0.01 ; * * *$ represents $\mathrm{p}<0.001 ;+$ represents $\mathrm{P}<0.10$ 
It can be seen from the Table 4 that high GAEI group have higher level of $\operatorname{WGEI}(F=5.858, p=<0.05)$, adopt more cooperative behavior $(F=8.661, p<0.01)$ and less competitive behavior $(F=4.108, p<0.05)$, have higher level of process satisfaction( $F$ $=14.616, p<0.001)$ and cohesion $(F=7.302, p<0.01)$. High $G L E I$ have higher group emotional adjustment ability $(F=2.852, p<0.10)$. Table 4 reveals that $G A E I$ and $G L E I$ have significant interaction in the cohesion variable.

Table 5. Means for Significant Dependent Variables in Different Groups

\begin{tabular}{lccccccc}
\hline & WGEI & GRE & GIUE & COO & COM & PS & COH \\
\hline GAEIH & 3.76 & 3.90 & 3.59 & 3.12 & 1.91 & 4.31 & 4.22 \\
GAEIL & 3.48 & 3.58 & 3.29 & 2.82 & 2.10 & 3.91 & 3.89 \\
GLEIH & - & 3.86 & - & - & - & - & - \\
GLEIL & - & 3.60 & - & - & - & - & - \\
\hline
\end{tabular}

From the Table 5 we can see that different levels of GAEI have different whole group emotional intelligence, cooperative behavior, competitive behavior, process satisfaction and cohesion. Different levels of GLEI group have different group emotional adjustment ability.

Table 6. Difference of Means for Group Cohesion in Different Manipulation Conditions

\begin{tabular}{|c|c|c|c|c|c|c|}
\hline $\begin{array}{l}\text { Dependent } \\
\text { Variable }\end{array}$ & Group(I) & Group $(\mathrm{J})$ & $\begin{array}{l}\text { Mean } \\
\text { Difference } \\
\text { (I-G) }\end{array}$ & $\begin{array}{l}\text { Group(I } \\
\text { ) }\end{array}$ & $\operatorname{Group}(\mathrm{J})$ & $\begin{array}{l}\text { Mean } \\
\text { Difference } \\
\text { (I-G) }\end{array}$ \\
\hline \multirow[t]{6}{*}{$\mathrm{COH}$} & $\begin{array}{l}\text { GLEIH- } \\
\text { GAEIH }\end{array}$ & $\begin{array}{l}\text { GLEIH- } \\
\text { GAEIL }\end{array}$ & 0.03 & $\begin{array}{l}\text { GLEIH- } \\
\text { GAEIL }\end{array}$ & $\begin{array}{l}\text { GLEIH- } \\
\text { GAEIH }\end{array}$ & -0.03 \\
\hline & & $\begin{array}{l}\text { GLEIL- } \\
\text { GAEIH }\end{array}$ & -0.07 & & $\begin{array}{l}\text { GLEIL- } \\
\text { GAEIH }\end{array}$ & -0.11 \\
\hline & & $\begin{array}{l}\text { GLEIL- } \\
\text { GAEIL }\end{array}$ & $0.25^{*}$ & & $\begin{array}{l}\text { GLEIL- } \\
\text { GAEIL }\end{array}$ & $0.24^{*}$ \\
\hline & $\begin{array}{l}\text { GLEIL- } \\
\text { GAEIH }\end{array}$ & $\begin{array}{l}\text { GLEIH } \\
\text { GAEIH }\end{array}$ & 0.08 & $\begin{array}{l}\text { GLEIL- } \\
\text { GAEIL }\end{array}$ & $\begin{array}{l}\text { GLEIH- } \\
\text { GAEIH }\end{array}$ & $-27^{*}$ \\
\hline & & $\begin{array}{l}\text { GLEIH- } \\
\text { GAEIL }\end{array}$ & 0.10 & & $\begin{array}{l}\text { GLEIH- } \\
\text { GAEIL }\end{array}$ & $-0.23^{*}$ \\
\hline & & $\begin{array}{l}\text { GLEIL- } \\
\text { GAEIL }\end{array}$ & $0.32^{* *}$ & & $\begin{array}{l}\text { GLEIL- } \\
\text { GAEIH }\end{array}$ & $-0.33^{* *}$ \\
\hline
\end{tabular}

Note: * represents $\mathrm{p}<0.05 ; * *$ represents $\mathrm{p}<0.01$

It can be seen from the table 6 that the group cohesion under GLEIH-GAEIH, GLEIHGAEIL, and GLEIL-GAEIH conditions are significantly superior to GLEIL-GAEIL condition, but there are no distinct difference among GLEIH-GAEIH, GLEIH-GAEIL and GLEILGAEIH conditions.

Based on the above analysis, assumption 1, 5 and 7 are fully verified, assumption 2 is partly verified, and other assumptions are not verified.

\section{Discussion}

(1) The relationship among three features of group emotional intelligence

The results of variance analysis show that high GAEI group has higher level of WGEI (Assumption1), especially the group emotional regulation and group emotional interpersonal 
understanding ability better. Thus it can be seen that the individual emotional intelligence level of group members can affect the ability of group manage emotions. If the individual emotional intelligence levels of group members are higher, they can comprehend each other's feelings, and make rapid reaction, thus form a kind of good behavior criterion. To the contrary, the low GAEI groups don't understand each other well, so it is difficult to form such an ability of dealing with collective emotion.

High GLEI group have higher level of group regulation ability (Assumption 2), which suggests that high emotional intelligence leaders often advocate for emotion reaction of each member, thus ensure the ability of whole group emotion regulation to be strong. If the group has a high emotional intelligence leader, he often encourages everybody to express the positive emotion, and reduce the negative emotions enormously, thus creating a positive collective behavior criterion. In this study, different level of GLEI group has no conspicuous differences in GSAE, GUE and GIUE dimensions. The possible reason is that interaction time of decision task is short, and group emotional intelligence is a kind of ability need long-term training, leader is hard to lead such a group behavior criterion established in such a short time. We will adopt longitudinal experiment and field work to make up the insufficiency in the future research.

(2)The relationship between Group Emotional Intelligence and Group Decision-making Results

Previous researches achieve group decision-making results through self-report questionnaire and expert scoring, which pay more attention to group interactive performance. In this study, we compare group ranking with expert ranking to gain group performance, which can not reflect the interaction process very well. This may be the main reason that the group decision-making performance (Assumption3 and 4) have no obvious difference among different groups.

Groups with different levels of $G A E I$ have noticeable difference in process satisfaction and group cohesion (Assumption5 and 7). High GAEI group can maintain good interpersonal relationship in decision-making process, and take more cooperative behavior and less competitive behavior. These positive behaviors ensure that members can fully express their opinions, and actively participate in the group interaction process, which make it is easier to obtain higher process satisfaction. High GAEI group can cultivate group emotional intelligence criterion which is the foundation of producing high sense of trust and identity. So high GAEI group members can integrate successfully into the group, and have confidence in group, and then produce high cohesion. In contrast, Low GAEI group due to lack of mutual understanding and trust, take more competitive behavior, which lead to reduction of the whole group participation and low process satisfaction and cohesion.

Through the further regression analysis to variable of WGEI and group outcome variable, we find that there is a strong correlation between the whole group emotional intelligence and process satisfaction $(t=3.739, p<0.001)$, the whole group emotional intelligence and cohesion $(t=5.808, p<0.001)$ is also strong correlation. Groups with different level of GLEI have no significant differences in process satisfaction and group cohesion (Assumption6 and 8), which may be related with the experimental design, for the reason that leadership cannot play out in a short period of time.

Under GLEIH-GAEIH, GLEIH-GAEIL, GLEIL-GAEIH conditions, group cohesion is significant higher than that under GLEI-GAEIL condition. Through the operation test of variance analysis, the group average emotional intelligence under GLEIH-GAEIH, GLEIHGAEI, GLEIL-GAEIH conditions is conspicuously higher than that under GLEIL-GAEIL condition, which further verifies the conclusion that high $G A E I$ groups tend to have better decision result. Group cohesion under GLEIH-GAEIL condition is markedly higher than that 
under GLEI-GAEIL condition, which supports Assumption 8, and leader emotional intelligence is also very important to work. Especially for low GAEI group, a leader with high leadership emotional intelligence can give full play to his leadership, and guide group unite and work together.

\section{Conclusions}

This paper verified that the group emotional intelligence is importance for group decisionmaking under emergency. This paper puts forward a preliminary research framework; it still needs large sample study and various empirical methods to verify. There is no mature group emotional intelligence measuring scale in the domestic, and this paper is to make a preliminary attempt, try to open the black box of group decision emotional process.

\section{Acknowledgements}

This research was supported by the Humanities and Social Science Youth Fund Project of Chinese Ministry of Education (No.13YJC630015), the Heilongjiang Natural Science Foundation (No.F201341), Fundamental research funds for the central university (No.HEUCF140902), and the Heilongjiang Postdoctoral Science Research Foundation (No.LBH-Q12123).

\section{References}

[1] L. Xue, "Global public governance: the important topic of Chinese public management research in the next 30 years", Journal of Public Administration, vol. 1, (2012), pp. 16-19.

[2] N. R. F. Maier, "Problem-solving Discussions and Conferences: Leadership Methods and Skills", New York: McGraw Hill, (1963), pp. 68-73.

[3] S G Green and T D Taber, "The effects of social decision schemes on decision group process", Organizational Behavior and Human Performance, vol. 25, (1980), pp. 97-106.

[4] W. Lei, X. Youmin and L. Hui, "Effects of task type and GSS on group outcomes: Laboratory experiment study", Journal of Management Sciences in China, vol. 10, (2007), pp. 86-96.

[5] B. A. Reing, "Toward an understanding of satisfaction with the process and outcomes of teamwork", Journal of Management Information Systems, vol. 19, (2003), pp. 65-83.

[6] K. A. Bollen and R. H. Hoyle, "Perceived cohesion: A conceptual and empirical examination", Social Forces, vol. 69, (1990), pp. 479-504.

[7] V. U. Druskat and S. B. Wolff, "Building the emotional intelligence of groups", Harvard Business Review, vol. 79, (2001), pp. 81-90.

[8] C. Hamme, "Group Emotional Intelligence: The Research and Development of an Assessment Instrument", Dissertation, The State University of New Jersey, (2003).

[9] S. Côté, "Group emotional intelligence and group performance", Research on Managing Groups and Teams: Affect and Groups, vol. 10, (2007), pp. 309- 336.

[10] T. Wang, "Team emotional intelligence and enterprise development", Sino Foreign Management, vol. 10, (1998), pp.14- 15.

[11] L. Bing, X. Ji and J. Chen, "The management of emotional quotient in knowledge teamwork", Science and Technology Management Research, vol. 6, (2004), pp. 43- 45.

[12] E S Koman and S B Wolff, "Emotional intelligence competencies in the team and team leader: A multi-level examination of the impact of emotional intelligence on group performance", Journal of Management Development, vol. 27, (2008), pp. 55-75.

[13] D. Tjosvold, C. Hui and Z. Yu, "Conflict management and task reflexivity for team in-role and extra-role performance in China", International Journal of Conflict Management, vol. 14, (2003), pp. 141-163.

[14] P D. Bliese, "Within-group Agreement, Non-independence and Reliability: Implications for Data Aggregation and Analysis//In. K. Klein \& S. W. Kozlowski (Eds.), Multilevel Theory, Research and Methods in Organizations. San Francisco: Jossey-Bass, pp 349-381( 2000) 


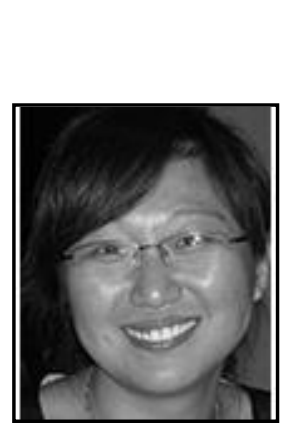

\section{Author}

Yingxin Chen, School of Economics and Management, Harbin Engineering University, associate professor, research field are crisis management, modeling and simulation. 
International Journal of Hybrid Information Technology Vol. 7, No. 6 (2014) 